\title{
Eindtermen voor de bacheloropleiding geneeskunde
}

\author{
R.F.J.M. Laan • J.A. Bulte • H.E.M. Daelmans • H.A. \\ M. Snellen-Balendong • J.C.C. Borleffs
}

Samenvatting Vijf van de acht opleidingen geneeskunde hebben besloten de bachelor/master-structuur in te voeren. Ten behoeve van het accreditatieproces zijn gemeenschappelijke eindkwalificaties van de bacheloropleiding geformuleerd. De eindkwalificaties bestaan uit een profiel van de bachelor geneeskunde en uit eindtermen van de bacheloropleiding. Volgens de opgestelde eindkwalificaties heeft de bachelor geneeskunde aantoonbare vorderingen gemaakt in ieder van de vier in het Raamplan 2001 artsopleiding onderscheiden aspecten: medische aspecten, wetenschappelijke aspecten, persoonlijke aspecten en aspecten met betrekking tot de maatschappij en het gezondheidszorgsysteem. De eindtermen zijn afgeleid van het raamplan, maar in algemene zin uitgewerkt op een niveau dat past bij de fase van de opleiding. De beoordelingscommissie van de Quality Assurance Netherlands Universities (QANU) heeft een positief oordeel over profiel en eindtermen uitgesproken. De NederlandsVlaamse Accreditatie Organisatie (NVAO) heeft op basis van dat oordeel de accreditatieaanvragen van de betreffende faculteiten gehonoreerd en in een definitief accreditatiebesluit vastgelegd. (Laan RFJM, Bulte JA, Daelmans HEM, Snellen-Balendong HAM, Borleffs JCC. Eindtermen voor de bacheloropleiding geneeskunde. Tijdschrift voor Medisch Onderwijs 2007;26 (1):19-29.)

\section{Inleiding}

In het Nederlands hoger en universitair onderwijs is de afgelopen jaren een stelsel van bachelor- en masteropleidingen ingevoerd. De geneeskundeopleidingen hebben zich tot onlangs aan deze stelselwijziging onttrokken en zijn, met toestemming van de minister, georganiseerd gebleven als ongedeelde opleidingen. $\mathrm{Na}$ het verschijnen van het Visitatierapport geneeskunde in 2004 hebben vijf universiteiten echter besloten om via een aanvullende procedure accreditatie te vragen voor een bachelor- en masteropleiding geneeskunde. Onderdeel van de aanvullende procedure is dat de eindtermen van beide opleidingen moeten worden geformuleerd en ter beoordeling voorgelegd. De betrokken opleidingsdirecteuren hebben een gezamenlijke werkgroep ingesteld, die heeft geadviseerd over profiel en eindtermen van de bacheloropleiding geneeskunde.

Het in december 2004 uitgebrachte advies is door de opleidingen overgenomen en als basis gebruikt voor de aanvullende beoordelingen. Inmiddels heeft, na een positieve advisering door de Quality Assurance Netherlands Universities (QANU), de Nederlands-Vlaamse Accreditatie Organisatie (NVAO) de accreditatieaanvragen van de betreffende faculteiten gehonoreerd en in een definitief accreditatiebesluit vastgelegd.

\section{Kaders voor profiel en eindtermen}

Het profiel en de eindtermen voor de bachelor- en masteropleiding geneeskunde zijn ontwikkeld voor gebruik in de aanvullende procedure met het oog op het verkrijgen van accreditatie. De NVAO heeft criteria geformuleerd waaraan de eindtermen worden getoetst. Deze criteria zijn weergegeven in tabel 1. Het tweede criterium maakt melding van internationaal geaccepteerde kwalificaties van een bachelor. Deze zijn tijdens een bijeenkomst in Dublin in 2002 geformuleerd door een werkgroep van het Joint Quality Initiative 
Tabel 1 Criteria voo de eindtermen uit het NVAO-toetsingskader.

1. De eindkwalificaties van de opleiding sluiten aan bij de eisen die door (buitenlandse) vakgenoten en de beroepspraktijk gesteld worden aan een opleiding in het betreffende domein (vakgebied/discipline en/of beroepspraktijk).

2. De eindkwalificaties van de opleiding sluiten aan bij algemene, internationaal geaccepteerde beschrijvingen van de kwalificaties van een bachelor.

3. De eindkwalificaties zijn ontleend aan eisen vanuit de wetenschappelijke discipline, de internationale wetenschapsbeoefening en voor daarvoor in aanmerking komende opleidingen de relevante praktijk in het toekomstige beroepenveld.

4. Een WO-bachelor heeft de kwalificaties voor toegang tot tenminste één verdere WO-studie op masterniveau en eventueel voor het betreden van de arbeidsmarkt.

Tabel 2 Nederlandse vertaling van de Dublin descriptoren.

\begin{tabular}{ll} 
& Kwalificaties bachelor \\
\hline Kennis en inzicht & Heeft aantoonbare kennis van en inzicht in een vakgebied. Hierbij wordt voortgebouwd op
\end{tabular}
het niveau dat is bereikt in het voortgezet onderwijs en dit wordt overtroffen.

Functioneert doorgaans op een niveau waarop met ondersteuning van gespecialiseerde handboeken, enige aspecten voorkomen waarvoor kennis van de laatste ontwikkelingen in het vakgebied vereist is.

Toepassen kennis en inzicht

Oordeelsvorming

Communicatie

Leervaardigheden
Is in staat om zijn/haar kennis en inzicht op dusdanige wijze toe te passen, dat dit een professionele benadering van zijn/haar werk of beroep laat zien, en beschikt verder over competenties voor het opstellen en verdiepen van argumentaties en voor het oplossen van problemen in het vakgebied.

Is in staat om relevante gegevens te verzamelen en interpreteren (meestal binnen het vakgebied) met het doel een oordeel te vormen dat mede gebaseerd is op het afwegen van relevante sociaal-maatschappelijke, wetenschappelijke of ethische aspecten. Is in staat om informatie, ideeën en oplossingen over te brengen op een publiek bestaande uit specialisten of niet-specialisten.

Bezit de leervaardigheden die noodzakelijk zijn om een vervolgstudie die een hoog niveau (www.jointquality.org) en staan bekend als de Dublin descriptoren. Zij zijn weergegeven in tabel 2.

Het profiel en de eindtermen moeten daarnaast natuurlijk ook realiseerbaar zijn in duur van de opleiding. Wettelijk is vastgelegd dat de bachelor- én de masteropleiding ieder drie jaren duren met jaarlijks 1680 studiebelastingsuren of 60 studiepunten (European Credit Transfer System, ECTS).

\section{Raamplan 2001 artsopleiding}

De eindtermen van de ongedeelde artsopleiding zijn vastgelegd in het Raamplan 2001 artsopleiding.1 Het algemene deel van dit raamplan bevat een profiel van de basisarts, de eindtermen van de opleiding en een lijst van problemen die uitgangspunt zijn voor het onderwijs. De eindtermen uit het raamplan zijn ook van toepassing op de masteropleiding. Voor de bacheloropleiding zijn een eigen profiel en eindtermen opgesteld. Omdat de bacheloropleiding voornamelijk de functie heeft voor te bereiden op de masteropleiding geneeskunde, is het Raamplan 2001 artsopleiding ook richtinggevend geweest voor het profiel en de eindtermen van de bacheloropleiding. De problemen die gezamenlijk de problemenlijst van het raamplan vormen, zijn ook in de bachelorfase uitgangspunten voor het onderwijs.

\section{Profiel van de bachelor geneeskunde}

De bachelor geneeskunde:

1. heeft aantoonbare vorderingen gemaakt in het bereiken van de eindtermen van de artsopleiding zoals genoemd in het Raamplan 2001 artsopleiding. De vorderingen betreffen de vier in het raamplan onderscheiden aspecten: medische aspecten, wetenschappelijke aspecten, persoonlijke aspecten en aspecten met betrekking tot de maatschappij en het gezondheidszorgsysteem.

2. heeft aantoonbare basisvaardigheden professioneel gedrag die voor het functioneren in de gezondheidszorg relevant zijn.

3. heeft aantoonbare kennis van en inzicht in de voor de geneeskunde relevante wetenschapsgebieden, inclusief de recente ontwikkelingen daarbinnen. 
4. is in staat om zijn/haar kennis, inzicht en vaardigheden op professionele wijze toe te passen binnen de gezondheidszorg en de medische wetenschappen.

5. is in staat om relevante gegevens op het gebied van de medische wetenschappen te verzamelen en te interpreteren met het doel een oordeel te vormen dat mede gebaseerd is op het afwegen van relevante sociaalmaatschappelijke, wetenschappelijke of ethische aspecten.

6. is in staat om informatie, ideeën en oplossingen over te brengen op een publiek bestaande uit specialisten of nietspecialisten.

7. bezit de leervaardigheden die noodzakelijk zijn om een vervolgstudie die een hoog niveau van autonomie veronderstelt aan te gaan.

\section{Eindtermen van de bacheloropleiding}

In het Raamplan 2001 artsopleiding worden eindtermen geformuleerd in vier gebieden: medische aspecten, wetenschappelijke aspecten, persoonlijke aspecten en aspecten in relatie tot de maatschappij en het gezondheidszorgsysteem. In ieder van die gebieden zijn er eindtermen die reeds in de bacheloropleiding in belangrijke mate kunnen worden gerealiseerd. De voor de bacheloropleiding geselecteerde eindtermen worden in de bijlage opgesomd (zie bijlage). Steeds worden daarvoor de volgende formuleringen gebruikt: "de bachelor geneeskunde beschikt over kennis en/of inzicht' (kennis), 'de bachelor geneeskunde is in staat' (vaardigheden) en 'de bachelor geneeskunde geeft blijk van' (professioneel gedrag).

Bij een vergelijking van de eindtermen van de bacheloropleiding met die van de basisartsopleiding als geheel zal blijken, dat veel eindtermen uit het raamplan ook als eindterm van de bacheloropleiding zijn opgenomen. Dit kan tot misverstanden leiden als men zich niet realiseert, dat het niveau waarop de eindtermen worden nagestreefd voor beide fasen van de opleiding verschilt. Dat een eindterm al nagestreefd wordt tijdens de bacheloropleiding betekent niet, dat de studenten zich op die gebieden in het tweede deel van de opleiding niet verder hoeven en zullen ontwikkelen. Dit geldt zowel voor kennis en inzicht, vaardigheden als professioneel gedrag. Een soortgelijke vaststelling kan overigens worden gedaan voor de eindtermen van de ongedeelde opleiding: artsen blijven binnen het medisch opleidingscontinuüm, ook na het artsexamen, het bereiken van de eindtermen op een steeds hoger niveau nastreven.

De bachelor zal vooral kennis en inzicht op hoofdlijnen hebben en kunnen toepassen, terwijl de master kennis en inzicht enerzijds zal hebben verdiept en anderzijds hebben verbreed naar bijzondere situaties. De bachelor zal zijn vaardigheden vooral kunnen tonen in minder complexe situaties, terwijl de master adequaat kan omgaan met meer gecompliceerde problematiek. Eindtermen uit het Raamplan 2001 artsopleiding die vooral betrekking hebben op die meer complexe situaties zijn daarom niet in de eindtermen van de bacheloropleiding opgenomen. De bachelor zal zijn professioneel gedrag tonen in situaties waarin hij als leerling-arts een relatie met een (simulatie) patiënt aangaat, maar ook in situaties waarin hij als student te maken heeft met andere studenten en met begeleiders. Bij de master zal het accent veel meer komen te liggen op professionaliteit in de arts-patiëntrelatie en in de relaties met andere professionals in de zorg.

\section{Toetsing aan het NVAO-kader}

Voldoen het profiel en de eindtermen aan het eerder geschetste en in tabel 1 weergegeven kader? Het eerste criterium van het NVAO-toetsingskader houdt in dat de kwalificaties moeten aansluiten bij de eisen die door vakgenoten en de beroepspraktijk worden gesteld. De aansluiting bij het Raamplan 2001 artsopleiding, die tot stand is gekomen na uitgebreide consultaties, biedt hiervoor voldoende garanties. Het overeengekomen profiel en de eindtermen sluiten ook goed aan bij de globale beschrijving van de bachelor geneeskunde in het rapport De arts van straks dat eveneens tot stand kwam door samenwerking tussen vele organisaties in de gezondheidszorg en de samenwerkende Nederlandse faculteiten geneeskunde. 2

Er zijn geen vergelijkbare documenten uit andere landen waarin een profiel en eindtermen van de bachelor geneeskunde zijn beschreven. Alleen in België is de bachelor/master-structuur ook ingevoerd bij geneeskunde. Ook daar is vastgesteld dat de bachelor in de geneeskunde specifiek voorbereidt op de master in de geneeskunde en dat haar doelstellingen daarom volledig in het licht gezien kunnen worden van de eindtermen van de ongedeelde initiële opleiding.

Het tweede criterium verwijst naar de Dublin descriptoren zoals die vermeld staan in tabel 2. Het opgestelde profiel van de bachelor geneeskunde weerspiegelt alle elementen in de Dublin descriptoren.

Het derde en vierde criterium van het NVAO-toetsingskader verwijzen naar de wetenschappelijke oriëntatie. Het Raamplan 2001 artsopleiding bevat een hoofdstuk 'wetenschappelijke aspecten'. De in deze paragaaf van het raamplan opgenomen eindtermen met relatie tot de grondbeginselen van wetenschappelijk onderzoek en de betekenis van wetenschappelijk denken voor het handelen van de arts, zijn overgenomen in de eindtermen van de bacheloropleiding. De afgestudeerde 
bachelor geneeskunde krijgt toegang tot de masteropleiding geneeskunde.

Het profiel en de eindtermen zijn inmiddels ook beoordeeld door de commissie die de aanvullende beoordelingen heeft verricht. Deze commissie bestond uit leden van de visitatiecommissie 2004 en werd voorgezeten door prof. dr. H.J. Huisjes. De commissie concludeert dat het profiel en de eindtermen "(...) een zinvolle invulling vormen van het wettelijk kader waarbinnen de opleidingen geneeskunde in Nederland opereren en een goede inhoudelijke aanpassing van dat kader voor de bacheloropleidingen." De commissie “(...) beschouwt het document als de pendant van het raamplan voor de bacheloropleidingen." 3 In de individuele rapporten van de vijf aanvragende instellingen heeft de commissie steeds ook vastgesteld dat de aangeboden programma's het aannemelijk maken dat het profiel en de eindtermen in de drie beschikbare jaren gerealiseerd kunnen worden.

\section{Verschillen tussen opleidingen?}

Doordat de betrokken faculteiten het advies van de werkgroep hebben overgenomen en door het positieve oordeel van de beoordelingscommissie, zijn het profiel en de eindtermen nu feitelijk nationaal vastgelegd. De betrokken faculteiten blijven uiteraard zelf verantwoordelijk voor het vaststellen van een programma voor hun bacheloropleiding en het valt te verwachten dat tussen de opleidingen programmatische verschillen zullen blijven bestaan. Zo zullen tussen de faculteiten verschillen kunnen bestaan in de selectie van problemen die reeds in de bacheloropleiding aandacht krijgen. Ook zullen verschillen bestaan in de werkvormen die binnen de opleiding worden ingezet. De faculteiten hebben wel uitgesproken dat het realiseren van het profiel en de eindtermen alleen mogelijk is, indien de studenten ook tijdens de bacheloropleiding geconfronteerd worden met en kunnen oefenen in de praktijk van de geneeskunde. De wijze waarop dit vorm krijgt, kan en zal daarbij per opleiding verschillen. De te verwachten programmatische verschillen hebben ook gevolgen voor het gemak waarmee studenten na de bacheloropleiding naar een masteropleiding geneeskunde aan een andere universiteit kunnen switchen. Iedere opleiding zal in zijn onderwijs- en examenregeling moeten vastleggen onder welke voorwaarden dat bij hen mogelijk is.

\section{Toekomstige ontwikkelingen}

Het medisch opleidingscontinuüm is volop in beweging. Opleidingen worden in toenemende mate gestuurd door beschrijvingen van te realiseren competenties. Zo heeft het Centraal College Medische Specialismen (CCMS) een set van algemene competenties vastgesteld die richting moeten geven aan de opleiding tot medisch specialist. Het is denkbaar dat ook de opleidingseisen voor de basisarts op vergelijkbare manier opnieuw worden vastgelegd. Dat zal dan gelden voor zowel de bacheloropleiding als de masteropleiding. De gezamenlijke Nederlandse decanen geneeskunde zullen waarschijnlijk binnenkort het initiatief nemen voor een dergelijk project waarbinnen ook ruimte zal zijn voor de inhoudelijke heroverwegingen die nodig zijn in verband met ontwikkelingen in de medische wetenschappen, de gezondheidszorg en de bredere maatschappelijke context.

Belangenconflict: geen gemeld.

Financiële ondersteuning: geen gemeld.

\section{Summary}

The majority of Dutch medical schools have decided to introduce a two cycle system in undergraduate medical training. The initial cycle is known as the bachelor study of medicine and the second cycle as the master study of medicine. A joint committee has drawn up a profile and general objectives for the bachelor study of medicine. After the bachelor study of medicine the student has demonstrated progress in each of four aspects that are included in the Blueprint 2001, training of doctors in the Netherlands: medical aspects, scientific aspects, personal aspects and aspects related to society and the health care system. The general objectives are all derived from the Blueprint 2001 but formulated on a level that is appropriate for the initial cycle. The Quality Assurance Netherlands Universities has approved the profile and general objectives. (Laan RFJM, Bulte JA, Daelmans HEM, Snellen-Balendong HAM, Borleffs JCC. Objectives of the bachelor study of medicine. Dutch Journal of Medical Education 2007;26(1):19-29.)

Bijlage: Eindtermen van de bacheloropleiding geneeskunde

\section{Medische aspecten}

1.1 De mens als somatisch, psychisch en sociaal wezen

De bachelor geneeskunde beschikt op hoofdlijnen over kennis en inzicht met betrekking tot:

1. de somatische, psychische en sociale structuur en functies van mensen, individueel en in hun onderlinge relatie.

2. de verschillen daarin die samenhangen met geslacht, leeftijd en culturele achtergrond.

3. de betekenis daarvan voor ziekte en gezondheid.

\subsection{Probleemherkenning en -omschrijving}

De bachelor geneeskunde is in staat:

1. te kijken en te luisteren naar de patiënt, naar de zin die de patiënt zelf aan de klacht geeft, waardoor een 
indruk van wensen en verwachtingen van de patiënt verkregen wordt.

2. het probleem en de hulpvraag van de patiënt te inventariseren en te benoemen.

\subsection{Anamnese}

De bachelor geneeskunde is in staat:

1. een anamnese op te nemen (huidige lichamelijke en psychische klachten, voorgeschiedenis, psychische en sociale omstandigheden) waarbij gelet wordt op zowel de medisch inhoudelijke kant als op communicatieve aspecten.

2. zowel systematisch als hypothesegericht anamnestische gegevens te verzamelen met betrekking tot de klacht en de reeds bestaande gevolgen ervan op lichamelijk, psychisch en sociaal gebied.

3. een heteroanamnese op te nemen.

\subsection{Lichamelijk onderzoek}

De bachelor geneeskunde is in staat:

1. algemeen lichamelijk onderzoek uit te voeren:

2. technisch adequaat.

3. zowel systematisch als gericht.

4. afwijkingen en symptomen te herkennen.

5. bevindingen juist te benoemen en te beschrijven.

\subsection{Probleemanalyse I}

De bachelor geneeskunde is in staat:

1. gegevens uit probleemomschrijving, anamnese, lichamelijk onderzoek en andere bevindingen te interpreteren en te evalueren.

2. systematisch een probleemlijst op te stellen op het vlak van lichamelijk, psychisch en sociaal functioneren.

3. hypothesen op te stellen over oorzaak en gevolg, resulterend in een differentiaal diagnose.

\subsection{Aanvullend onderzoek}

De bachelor geneeskunde beschikt over kennis met betrekking tot:

1. de mogelijkheden van aanvullend onderzoek en de principes van de uitvoering daarvan.

\subsection{Probleemanalyse II}

De bachelor geneeskunde is in staat:
1. opnieuw verbanden te leggen tussen gegevens uit probleemomschrijving, anamnese, lichamelijk onderzoek en eventueel verricht aanvullend onderzoek.

2. gemotiveerd te komen tot een waarschijnlijkheidsdiagnose die als uitgangspunt kan dienen voor advisering, behandeling en begeleiding.

\subsection{Beleid}

De bachelor geneeskunde is in staat:

1. het therapeutisch doel van een behandeling/beleid te bepalen.

De bachelor geneeskunde beschikt over kennis met betrekking tot:

1. mogelijkheden van interventie door paramedici en hulpverleners op het psychologische, sociale en pastorale vlak.

De bachelor geneeskunde beschikt over kennis met betrekking tot:

1. de verschillende typen van interventies die in de Nederlandse geneeskunde gebruikelijk zijn.

2. de grondbeginselen van de geneesmiddelenleer.

De bachelor geneeskunde is in staat:

1. basale eerste hulp te verlenen.

1.9 Begeleiding

De bachelor geneeskunde is in staat:

1. te zorgen voor een open en respectvolle communicatie.

De bachelor geneeskunde beschikt over kennis met betrekking tot de essentialia van:

1. het begeleiden van chronisch en ongeneeslijk zieken alsmede palliatieve zorg.

2. het voeren van een slecht nieuws-gesprek.

3. stervensbegeleiding.

4. het begeleiden van patiënt en diens betrokken anderen, ondermeer na het brengen van slecht nieuws.

\subsection{Verslaglegging en registratie}

De bachelor geneeskunde is in staat:

1. tot het leesbaar, systematisch, helder en toetsbaar vastleggen van:

2. de hulpvraag van de patiënt.

3. de bevindingen bij het diagnostisch proces (anamnese, lichamelijk onderzoek, probleemlijst, differentiële diagnosen, eventueel aanvullend onderzoek).

4. de ingestelde behandeling. 
5. de aan de patiënt en anderen gedane mededelingen.

6. de relevante gegevens mondeling en schriftelijk over te dragen.

7. bij het hanteren van medische dossiers rekening te houden met de privacy van de patiënt.

De bachelor geneeskunde beschikt over kennis op hoofdlijnen met betrekking tot:

1. de verschillende vormen van verslaglegging met inbegrip van die met behulp van informatie- en communicatietechnologie.

\subsection{Preventie en predictie}

De bachelor geneeskunde beschikt over kennis op hoofdlijnen met betrekking tot:

1. de gezondheidsrisico's op zowel individueel als collectief niveau en van de effecten van preventieve maatregelen.

2. veel voorkomende relaties tussen omgevingsfactoren (incl. fysische en chemische, zoals radioactieve straling) en ziekten.

3. vormen van preventie:

4. epidemiologische methodes van opsporing van gezondheidsproblemen en -bedreigingen, alsmede:

5. methodes van opsporing van risicopatiënten zoals screening, periodiek geneeskundig onderzoek, casefinding, screening binnen de eigen patiëntenpopulatie, monitoring, collectieve preventieprogramma's waaronder bevolkingsonderzoek.

6. de implicaties van erfelijkheidsonderzoek en antenatale diagnostiek.

\section{Wetenschappelijke aspecten}

2.1 Grondbeginselen van wetenschappelijk onderzoek

De bachelor geneeskunde is in staat:

1. weinig complex onderzoek te rapporteren, te interpreteren en te evalueren.

De bachelor geneeskunde beschikt over kennis met betrekking tot:

1. de algemene principes van hypothesevorming, methoden (waaronder die met betrekking tot gegevensverzameling), concepties van voor de geneeskunde relevante vormen van wetenschappelijk onderzoek.

2. de beginselen van wetenschapsmethodologie, biostatistiek en epidemiologie.

3. de denkwijze van het wetenschappelijk onderzoek (door actieve deelname).
2.2 Betekenis van het wetenschappelijk denken voor het handelen van de arts

De bachelor geneeskunde geeft blijk van:

1. een kritische houding ten opzichte van de wetenschappelijke kennis waarop het medisch handelen is gebaseerd.

De bachelor geneeskunde is in staat:

1. een gezondheidsprobleem systematisch te benaderen volgens de beginselen van evidence based medicine.

De bachelor geneeskunde beschikt over kennis met betrekking tot de wetenschappelijke achtergronden van:

1. de basisvakken noodzakelijk voor een goed begrip van de structuur (anatomie) en functie van het menselijk lichaam:

voor zover zij betrekking hebben op de te bestuderen afwijkingen en op de aangrijpingspunten voor diagnostiek en therapie.

1. ziekteleer, symptomatologie en diagnostiek, therapie en prognose.

2. preventieve gezondheidszorg.

2.3 Bevorderen en onderhouden van de vakbekwaamheid

Verantwoordelijkheid voor eigen

deskundigheidsbevordering

De bachelor geneeskunde geeft blijk van:

1. besef dat na de bacheloropleiding verdere scholing nodig is.

De bachelor geneeskunde is in staat:

1. eigen blinde vlekken en/of lacunes in de uitvoering van de taken op te sporen en te trachten deze op te heffen.

2. nieuw verworven inzichten toe te passen.

Bijhouden vakliteratuur

De bachelor geneeskunde is in staat:

1. informatie, die beroepshalve van belang is, in de literatuur of andere bronnen op te sporen, te beoordelen en over te dragen.

2. tot het actief opsporen van relevante literatuur (b.v. bibliotheek, informatiecommunicatietechnologiesystemen).

3. tot het refereren van vakliteratuur. 


\section{Persoolijke aspecten}

\subsection{Student-patiëntrelatie}

De bachelor geneeskunde geeft blijk van:

1. een open houding ten aanzien van patiënten.

2. een streven naar een zo gelijkwaardig mogelijke student-patiëntrelatie.

3. aandacht voor de wijze waarop de patiënt met zijn klacht(en) omgaat en de betekenis die de ziekte voor de patiënt heeft.

4. begrip voor de situatie van de patiënt (ook in uitzonderlijke omstandigheden) en diens sociale achtergrond.

5. besef van de afhankelijke positie van de patiënt.

6. inzicht in de rol die eigen gevoelens, remmingen, normen en waarden vervullen bij contact met een patiënt.

7. open te staan voor wensen en klachten, behoeften en verwachtingen van de patiënt.

\subsection{Persoonlijk functioneren}

\section{Met betrekking tot persoonlijke eigenschappen}

De bachelor geneeskunde geeft blijk van besef dat voor het functioneren als toekomstig arts vereist is, dat hij:

1. kan omgaan met onzekerheid.

2. verantwoordelijkheid kan dragen.

3. eigen beperkingen kan onderkennen.

\section{Met betrekking tot het medisch handelen}

De bachelor geneeskunde geeft in de verschillende onderwijssituaties blijk van besef dat het voor het functioneren als toekomstig arts vereist is, dat hij:

1. grenzen en mogelijkheden van de gegeven situatie, van de eigen taakvervulling en van de medische professie in het algemeen kan beoordelen.

2. zich in wil zetten en zich medeverantwoordelijk wil voelen voor het lichamelijke, geestelijke en sociale welzijn van mensen en voor alle vormen van gezondheidszorg.

3. zich verantwoordelijk voelt voor het bevorderen van de eigen (des)kundigheid en hierin eigen initiatieven ontplooit.

4. eigen gevoelens, normen en waarden onderkent in relatie tot existentiële vragen over leven, dood, ziekte en gezondheid en kan omgaan met medisch-ethische vragen.

5. verplicht is te handelen met in achtneming van het medisch beroepsgeheim.
6. medisch handelen in de beroepsmatige en in de privésfeer kan scheiden.

\section{Met betrekking tot het werken in teamverband}

De bachelor geneeskunde geeft blijk van besef dat voor het functioneren als toekomstig arts vereist is, dat hij:

1. in groepsverband kan functioneren.

2. bereid is zijn werk door anderen te laten beoordelen/ toetsen.

3. verschillende rollen binnen het teamverband op zich kan nemen.

4. om kan gaan met positieve en negatieve kritiek.

5. bereid is op tijd de mening van anderen te vragen.

6. vaardigheden hanteert met betrekking tot het overbrengen van informatie.

\section{Aspecten in relatie tot de maatschappij en het gezondheidszorgsysteem}

\subsection{Volksgezondheid en gezondheidszorg}

De bachelor geneeskunde beschikt over kennis op hoofdlijnen met betrekking tot de volksgezondheid:

1. de relatieve omvang van ziekte, handicap en sterfte en de verdeling daarvan in de bevolking.

2 de determinanten van de volksgezondheid waaronder demografische, culturele, sociale en economische factoren.

3 het belang zowel van preventie van langdurige arbeidsongeschiktheid als van het behoud van arbeidsgeschiktheid.

4 de organisatie, de medische consumptie, de gezondheidszorgvoorzieningen en de kwaliteitsbewaking van de gezondheidszorg in Nederland, incl. de belangrijkste overeenkomsten en verschillen met andere gezondheidszorgsystemen in Europa en de rest van de wereld.

\subsection{Medische ethiek}

De bachelor geneeskunde geeft blijk van:

1. gevoel voor uiteenlopende morele opvattingen en respect voor andere meningen en opvattingen.

De bachelor geneeskunde is in staat:

1. ethische aspecten te herkennen die bij medische beslissingen in het spel zijn.

De bachelor geneeskunde beschikt over kennis op hoofdlijnen met betrekking tot: 
1. algemeen filosofische vragen in de geneeskunde: gezondheid en ziekte, lijden en dood.

2. algemene grondslagen van ethiek: mensbeeld, wereldbeeld en levensbeschouwing.

3. algemene vragen met betrekking tot ethiek: wat is een moreel probleem, ethiek en rationaliteit, ethiek en interculturalisatie, de verhouding tussen ethiek en recht.

4. de invloed van wetenschappelijke ontwikkelingen op normen en waarden.

5. de in Nederland meest voorkomende medisch-ethische opvattingen.

6. ethiek en medisch wetenschappelijk onderzoek.

4.3 Juridische aspecten van de gezondheidszorg en van de medische beroepsuitoefening

De bachelor geneeskunde beschikt over kennis op hoofdlijnen met betrekking tot:
1. grondslagen en beginselen van het gezondheidsrecht.

2. juridische aspecten van de arts-patiëntrelatie (algemeen en in bijzondere situaties).

3. beroepsgeheim en privacybescherming.

\section{Literatuur}

Metz JCM, Verbeek-Weel AMM, Huisjes HJ, editors. Raamplan 2001 artsopleiding. Bijgestelde eindtermen van de artsopleiding. Nijmegen: Mediagroep; 2001.

Meyboom-de Jong B, Schmit Jongbloed LJ, Willemsen MC, editors. De arts van straks. Een nieuw opleidingscontinuüm. Wijk bij Duurstede: Hentenaar; 2002.

QANU. Additionele beoordeling van de bacheloren masteropleiding Geneeskunde van de Radboud Universiteit Nijmegen. Utrecht; QANU: 2006. p. 5. 